\title{
Analysis of Middle Grades' Science Textbooks Based on the Active Learning
}

\author{
Dr. Al-Momani Fayhaa N. \\ Dept. of Education, Najran University, P. O. Box1988, Najran 61441, KSA
}

Tel: 966-583-256-161

E-mail: fnalmomani@nu.edu.sa; fa_momany@yahoo.com

Received: February 15, 2019 Accepted: March 15, 2019 Published: March 18, 2019

doi: 10.5296/ire.v7i1.14512

URL: https://doi.org/10.5296/ire.v7i1.14512

\begin{abstract}
The study aimed to analyse the series of natural sciences textbooks for the intermediate stage in the light of active learning in KSA. Two sources of data used: active learning activities card; content analysis card to measure the degree of involvement. The results showed the concentration of the middle textbook series on physical activities, while the students were weakly involved in intellectual activities, social activities were neglected, in addition; the integration activities were low. On the other hand, the values of the involvement coefficient of the natural sciences textbook series for the middle stage in light of the subject matter indicated that it is suitable and excellent, as well as; acceptable in the light of graphics, shapes and, but not satisfactory in activities Where students are involved in the practice of thinking and scientific inquiry in a few percentages. The study recommended that teachers should take into account the diversity of the forms of student activities in active learning during instruction.
\end{abstract}

Keywords: Active learning activities, Content analysis, Involvement, Natural sciences textbooks series for the intermediate stage

\section{Introduction}

Education is the development gate of nations; the powerful state is the one, which owns science, technology and thoughts. Therefore, most states have changed their view, with the advent of the third millennium, about education in general and the teaching of science in particular. So some reconsidered science curricula, which are considered the most ones in need of revision, analysis, evaluation, and development in the light of contemporary scientific trends and reform movements for scientific education that aimed to develop science and math curricula to be in line with the scientific and technical progress, and thereby to fulfil the needs of student and community and prepare the scientifically-educated citizen. 
Many reform movements appeared for the scientific curricula globally, especially after the issuance of the report, "a nation at risk" which recommended to have educational curricula rather more correlated with labour market and industrial need (National Commission on Excellence in Education, 1983) as: Science for all Americans (Project, 2061); Benchmarks for scientific literacy; Scope, sequence \& coordination (SS\&C); Interaction movement between Science, technology \& society (STS); National Science Education Standards (NSES) (Fagehe, 2009), which focused on unifying standards and themes with the aim to achieve quality and specificity in teaching sciences in agreement with the long-term prospective vision (Zaytoon, 2010). Which concentrates, as a whole, on the learner and his active role in the educational process to creating the learning, by engaging students in the activities that force them to think about the thoughts they generate and how to use such thoughts. This is what the Active Learning calls for, to maintain the students active in their learning mentally, physically and socially.

At the Arab level, many conferences and seminars were held to determine the standards that must be included in science curricula; including the scientific education symposium and development requirements in the 21 st century (1996), which aimed to shed light on the development of science curricula in the public education (Abd-Alsalam, 1996). The Kingdom of Saudi Arabia was among the first states that worked on the development of its curricula in order to develop human resources, to prepare the good and productive person and the interactive with the contemporary realities and future variables, so it made a quality leap in education through the project of science and math educational development which covered all education and teaching aspects including: building of natural sciences and math and their respective supporting educational materials (textbook/ teacher's manuals/ activity notebooks...), based on the global standards and criteria in agreement with the inputs of the reliable modern educational theories (MOE, 2006). Therefore, the project philosophy and vision focused on Learner-centred learning; Collaborative learning, and knowledge exchange and communicating to develop the skills of scientific, critical and innovative thinking, problem-solving, self-learning, collaborative learning and communication (Albesher \& Alzahrani, 2004; MOE, 2006). Where such standards are considered essential cornerstones and principles for the modern educational studies which concentrated on the AL and constructivist theory, and that most fit with what the proponents of active learning they have agreed upon in the intermediate classes; yet, the most endurable learning comes with immediate experiment and interaction with the intellectual, social and physical environments (Edwards, Kemp \& Page, 2014; Nesin, 2012; National Middle School Association (NMSA), 2010; Edwards, 2014).

Actually, the project of educational development in the KSA focused on that by the end of 2016 it's expected to have syllabuses and educational materials associated with all general school stages, according to international standards, realizing the project vision represented in a learning cantered on the leaner, scientific inquiry, collaborative learning, self-learning and communication, which can all be achieved by the active learning (Edwards, 2015). And, in order to verify the reflection and inclusion of such standards in the Natural science textbooks for the intermediate stage; it is important to detect how the Natural science textbooks activate the student role in achieving convenience with the content to operationalize the active learning 
using the relevant standards: such as involvement standard in the content analysis, and the criterion of the diversified AL promoting activities is their integration together, which would develop the learner's intellectual, physical, and social skills to solve the problems.

\subsection{Problems and Questions of the Study}

Active learning is facing many barriers and challenges including the content challenges, so Edward (2015) was disclosed that the convenience with the content and deep understanding of it and being suitable to the students would lead to educating the active learning. And, as the textbook it he visible part of curriculum, and he vessel that contains the study material in which the content is embodied, Especially, books of the intermediate stage which prepares and sets up the student to the secondary stage.

Based on the importance of the textbook and its role as first ally to the learner from which active learning must get launched, and under many assertions on the necessity to have textbooks suitable to the students as regards their readability, degree of difficulty, and the extension of access, for the students, to participate and express their views through conscious questions, and interesting activities included, so this output must be evaluated and assessed on continuous basis to ensure that its specs and content are compatible with the standards required, and to develop it in a way to achieve the delicate balance and targets it would realize. However, the analysis of textbooks content, in light of a definite standards, maybe the base for that. Accordingly, this study is presented to provide evidences on how the Natural science textbooks, for the intermediate stage, are effective for the student in active learning and, the level of including and making the active learning operational therein; and specifically, the study aimed to answer the following question: how the natural science textbooks of the intermediate stage (1-3) are effective for the student in active learning?

To answer this key question, we need to answer the following sub-questions:

1) To what extent the activities of active learning, included in the Natural science textbooks for the intermediate stage, diversified?

2) To what degree the Natural science textbooks for the intermediate stage do involve the student in AL in the KSA?

\subsection{Significance of the Study}

The importance of study comes from the significance of the elements addressed; as it focuses on the two most important elements of the curriculum elements, namely: the book and the learner, and the relation between them. Which assumed to be based on the dynamic positive interaction stimulating the active learning centered on the learner, so that the learner is directed to do diverse activities, and compelled to think about the ideas presented and plan for purposeful and useful learning, in many ways.

Moreover, the study tackled the textbooks of intermediate stage students, whose ages range between 13-15 years, and this young group characterized by being active, lively and prone to merge with the peers, and in being able to learn in various methods, which proves the importance of teaching them, in general, and the book as an ally, in particular.

The study draws its importance also, from the novelty of the standard which it addressed in 
analysis- active learning - and its consistency with modern education and learning trends and in particular for the intermediate stage, and the directions of the ministry of education to develop and analyze the curricula, for it may contribute to provide the feedback to officials in the ministry of education, planners of curricula and authors as well, about the reality of Natural science textbooks for the intermediate stage, that would help to develop new, active and effective curricula based on active learning in which students would actively and virtually participate, through understanding the texts, presentation of the educational material, simulation of figures and drawings of the learner thinking, enrich them with the activities that would motivate the student's thinking and provide him with the interactive activities, and entrust him with the performance of tasks by interacting with the intellectual, social and physical environments, and avoid the authoritarian books which provide answers and leave no room for the understanding stimulant to the student's thinking.

\section{Theoretical Underpinning}

\subsection{Active Learning}

Active learning considered among the modern concepts, the use of which became common in the last quarter of the twentieth century. The reason behind that ascribed to the report of Bonwell \& Eison (1991) of the association for higher education studies entitled, "active learning: creates interest in the classroom", which uncovered the features of active learning and methods of its application. Bonwell \& Eison (1991) defined active learning: "the educational activities in which the students participate and require them to do things and think about what they are doing". However, Carr, Palmer and Hagel (2015) defined as "the students' efforts to build their knowledge actively". However, the researcher sees that active learning is "the effective participation of students for building knowledge by self".

The techniques, which promote active learning have been defined as "activities render the students to do things other than writing down remarks or following the instructions, such as building the new knowledge and new scientific kills" (Handelsman, Miller, \& Pfund, 2007). Chan, Sidhu, \& Lee (2014) defined at the seventh Taylor Conference for learning and teaching as "educational activities in which students participate in doing things and thinking in what they are doing". However, the researcher finds that the active learning promoting techniques are: "cognitive educational activities in which students participate in doing things focusing on that, students must be fetched to the process of learning and compelled to think about what they are doing, within a vital environment based on dynamic interaction between the learner and the source of learning to acquire expertise".

Edwards (2014) proposed in her article "active learning in the intermediate classes" a description and planning of various types of teaching the active learning in the intermediate classes:

1) Intellectual activities: intended principally to engage the student intellectually in the content, so that they intellectually active instead of receiving the information passively, and accepting the control of teacher or textbook. However, active learning requires the students to interact with the content using critical thinking or higher levels of thinking; such as analysis or synthesis. 
2) Social activities: they are consider the most important activities for the intermediate classes, given their sensitive age span (10-15), so youth at adolescence focus on peers and prefer working collaboratively.

3) Physical activities: adolescent youth in the intermediate classes, need physical movement upon learning during the study, for they are extremely active and energetic due to their bodily growth and the changes they go through during puberty at this stage. Nevertheless, techniques of active learning concentrate on learning through hands-on, so the textbook has to engage the students in individual or collective practical activities such as experiments, design of education videos, and making models, instead of directing the facts and feeding them (Edwards, 2014; Nesin, 2012).

4) Integration activities: of course there are many of learning techniques which do more than one type of activities together, and this requires the learner to use multiple skills at the same time like using hands-on with minds-on, which would create better educational environment and different educational opportunities for the students, instigate persistence and zeal for learning ((Edwards, 2015).

In addition, gradation in active learning activities must be observed while being presented in the textbook, in accordance with student participation and the level of activities, from the simple, like writing an outline, reading and writing drills, and self-evaluation, to the complex, like self-learning and inverted chapters (Shannon \& Mayes, 2011).

\subsection{Involvement of Learner}

Involvement of student by the book is considered an important element of that of the content analysis. As, it has a role in highlighting the curriculum elements represented in the textbook. Moreover, textbook's involvement refers to what extent the textbook addresses and argues with the student without dictating the scientific material on him, also, reveals its capacity in deducting the scientific ideas in the style of scientific inquiry. This means that the textbook material must be presented in a manner renders the student participant and active in the educational process.

This concept comprises several kinds of textbook's involvement of the student in the light: presentation of educational material; drawings, figures and pictures; activities; and chapters' abstracts (Khataibeh, 2008). The extent to which the student is involved in the scientific material of the textbook can be determined through assessing the coefficient of textbook's involvement of the student using Romey's Formula, the first who used this method to assess the textbook's involvement of the student in presenting the material, drawings, figures, activities, and chapters' abstracts (Khataibeh, 2008). The coefficient of student involvement by the textbook, in the four areas mentioned above, refers to the rate of leaner's involvement in the learning when studying the textbook, and rate of the learner's personal activity through the textbook element, which is what sought by the active learning with the learner.

\section{Literature Review}

Many international and local studies addressed the analysis and evaluation of science textbooks' content from different and multiple aspects. In proportion to the educational 
directions, as per the time in which the study was conducted, for its role in disclosing the aspects of failure in developing and enhancing the curricula; also, this sort of studies search and renovate continuously for the importance of constant evaluation of the curriculum, and its constant development.

In the field of active learning, Edwards (2014) found that students should be intellectually active instead of receiving the information passively, and accepting the control of teacher or textbook by interacting with the content using critical thinking or higher levels of thinking such as analysis or synthesis.

Thereby, in the area of involvement, Fari (2016) study revealed deteriorated contribution coefficients to the area of content and activities, in having the students involved in the general science textbooks for the intermediate stage, and elevated level to the area of drawings, pictures and figures. In addition, the degree of content contribution differs by the class unlike all drawings, pictures, figures and activities that are not affected by the classroom. Furthermore, Zewdie (2014) analysis of physics textbooks for the seventh and eighth grades in the Ethiopian schools, which demonstrated that the textbooks focused on feeding of facts, explanations, and principles, and answers of the activities are direct from the books, and as for figures and drawings, it focused on demonstration only, yet they were developed in attractive colors.

However, on the level of Saudi literature. Al-Shahri (2010) study indicated to the availability of proposed standards with "poor range" in the themes of scientific material, manner of presentation, educational activities and evaluation in biology textbooks of the secondary grade courses, while the proposed standards were provided with "limited range" in the theme of pictures, figures and illustrations in both semesters.

From all of the above, we see diversity and multiplicity in the analytical studies of the international and local education literature, variation in results, and this may attributed to difference in science curricula from one country to another with the difference of stage and class. Current study characterized by addressing science textbooks for a whole stage (the intermediate) that encompass the first, second and third intermediate, in addition to tackling more than one standard of the content's analysis standards together. In addition, it focused on the analysis standards related to learner and reinforcing the active learning - considering that the textbook developed for the student and it is his permanent ally- like involvement; it also dealt with anther standard, not addressed by any study of content analysis before, which is activities forms and variety in employing the active learning in science textbook.

\section{Methodology}

Study followed the descriptive approach in the area of surveys, documentary analysis branch (textbooks' content analysis). Where, phenomenon evaluated analytically, as is it, through analyzing the content of natural science textbook for the intermediate stage, quantitatively and qualitatively.

\subsection{Population and Sample}

To reckon the involvement; study population consisted of all textbook within the series "advance natural science" applied to the intermediate stage classes (first/second/third 
intermediate), for the scholastic year 2018/2019, amounting to (6) books, inasmuch as one book per chapter. Moreover, research sample consisted of $20 \%$ of the total pages of each of such books in the systematic random method, which is an acceptable ratio for the surveys. Namely, at a rate of one page from among five pages, serially and consecutively, of each part of each book in order to estimate the content involvement, yet activity pages only were excluded- as book involvement will be determined through the activities- so the next page to the one excluded was analyzed.

In addition, all activities of the series books were analyzed to detect the variety of active-leaning activities.

\subsection{Material}

The study aimed to investigate how effective are the Natural science textbooks, of the intermediate stage, for the student in active learning. Therefore, the studly implemented the following tools:

1) Card of active learning activities: the researcher prepared card to detect how diverse are the activities of AL in the textbook, which composed of a list of active learning activities that can be provided in the textbook in their three types: intellectual, physical and social activities, in addition to integration activities that employ more than one type simultaneously.

Table 1. Types of active learning Activities: Objective and techniques of employment in active learning

\begin{tabular}{|c|c|c|}
\hline $\begin{array}{l}\text { Type of Active } \\
\text { Learning Activities }\end{array}$ & Objective & $\begin{array}{l}\text { Techniques off employment in } \\
\text { active learning. }\end{array}$ \\
\hline Intellectually & $\begin{array}{l}\text { Engage the student intellectually } \\
\text { in content, they interact with it } \\
\text { instead of receiving information } \\
\text { from a textbook negatively }\end{array}$ & $\begin{array}{ll}\text { - } & \text { Critical thinking } \\
\text { - } & \text { Thinking above cognitive } \\
\text { - } & \text { Mental competitions } \\
\text { - } & \text { Brainstorming } \\
\text { - } & \text { Problem Solving } \\
\text { - } & \text { Concept maps }\end{array}$ \\
\hline Physically & $\begin{array}{l}\text { Engage the student in vital } \\
\text { practical activities - individual or } \\
\text { collective- requires physical } \\
\text { movement during learning. }\end{array}$ & $\begin{array}{l}\text { - Hand-on work } \\
\text { - } \quad \text { Experiments and practical } \\
\text { presentations } \\
\text { - Design educational videos } \\
\text { - } \quad \text { Making models }\end{array}$ \\
\hline Socially & $\begin{array}{l}\text { Engage students with } \\
\text { peer-focused activities and work } \\
\text { cooperatively. The most } \\
\text { important types of activities. }\end{array}$ & $\begin{array}{l}\text { - Peer participation to discuss a } \\
\text { question about content } \\
\text { - } \quad \text { Large-Group Discussion } \\
\text { - } \quad \text { Think - pair - Share }\end{array}$ \\
\hline
\end{tabular}


Integration

Engage students in intellectual, physical and/or social activities at the same time.

- Create of project in small groups

- Collaborative inquiry

To be sure, of their validity, they were presented to experts in science curricula and teaching. Moreover, based on their remarks; modifications were introduced on the formulations of activities. Furthermore, reliability was counted by selecting and analyzing an educational unit by the researcher and another analyst, after he was duly trained on it use, then re-analysis was made after two weeks, and counted the compatibility ratio that reached $(0,93)$, and Kappa coefficient which reached (88\%) and thereby considered suitable for the purposes of study. The questionnaire was used to monitor the frequencies of the three AL activities in each of the intermediate stage books and, to calculate the percentage of each type thereof to judge them. In addition, each type was classified according to its level (simple/complex) while considering the gradation in activities during presentation in the book.

2) Content analysis card to measure the involvement extent: a card was developed to analyze the content of Natural science textbooks for the intermediate stage (grades 1-3). It included three sub-cards, according to the involvement elements and the analysis groups and unit were specified for each as follows.

Table 2. Content analysis cards for involvement calculation

\begin{tabular}{|c|c|c|c|}
\hline Card name & Categories of analysis & code & Unite of analysis \\
\hline Subject mater & - Words and facts & $\mathrm{a}$ & The actual, nominal or \\
\hline Analysis card & $\begin{array}{l}\text { - Explicit conclusions } \\
\text { generalizations }\end{array}$ & $\mathrm{b}$ & $\begin{array}{l}\text { semi-sentence } \\
\text { sentence gives full } \\
\text { meaning and ends with }\end{array}$ \\
\hline & $\begin{array}{l}\text { - Definitions } \\
\text { - Questions asked by the book and } \\
\text { answered directly }\end{array}$ & $\begin{array}{l}\mathrm{c} \\
\mathrm{d}\end{array}$ & $\begin{array}{l}\text { a comma, question } \\
\text { mark, or point of } \\
\text { content }\end{array}$ \\
\hline
\end{tabular}

- Questions that require students to $\mathrm{e}$ analyze information or pose a problem

- Questions that interest and interest $\mathrm{h}$ students are not answered directly

- Rhetorical questions i

- News sentences $t$

- Indicative sentences $\mathrm{u}$

- Guiding sentences $\quad \mathrm{z}$

Graphics, - Graphics or shapes used directly for a images and illustrative purposes.

Graphics, Images \& shapes except those 
shapes

Analysis card

Activity

Analysis card
- Graphics or shapes Students need to b perform an activity or use information

- Graphics or shapes that show how to install a particular device for a particular experiment

- Graphics or shapes do not fit into any d of the above categories

- Suggested activities for the student in the unit included in activities and calendar questions were used as illustrative purposes

Scientific activities
and
activities

Apparent validity of the three cards verified by presenting them to professionals in curricula and teaching and to science supervisors seeking their opinion about the cards suitability to the purpose they developed for.

However, the reliability of analysis tool, ten random pages were analyzed, by the researcher and another analyst after having been trained on analysis, from each book under investigation according to the standards contained in Romey's method, and after agreement on the coding unit of the content, drawings, figures and activities.

The process of analysis was repeated after about one month from the first analysis, whereby ratio of congruence between the analysts was calculated, which was as follows:

Table 3. The stability of the involvement elements' cards according to the ratio of the agreement of analysts

\begin{tabular}{llll}
\hline Card name & Reliability ratios & Kappa Coefficient & degree \\
\hline Subject matter Analysis card & 0.89 & $77 \%$ & strong \\
Graphics and shapes Analysis card & 0.95 & $90 \%$ & distinct \\
Activity Analysis card & 0.93 & $86 \%$ & distinct \\
\hline
\end{tabular}

We notice from Table 3 . that the values of reliability ratios for the cards of involvement elements fit the purpose of study. However, elevation in reliability values of the analysis tools of graphics, shapes, and scientific activities between the analysts, can be attributed to that, pictures of the book are crystal clear as they were shot by new cameras which would reduce the difference between the analysts. In addition, scientific activities listed in the book was highly clear with specific purpose, which would reduce the variation between he analysts.

\subsection{Statistical Analysis}

Data were analyzed using the descriptive quantitative analysis, and qualitative analysis of the data that have been obtained. So, arithmetic means, and percentage of frequency for each type of AL promoting activities were calculated. In addition, Romey's-formula was used for 
the involvement after calculating the percentages of involvement coefficient in the presentation of content, drawings, figures and activities.

Table 4. Equation of involvement

Types of textbooks involvement

Equation (Romey's formula)

Scientific subject

mater

$\sum$ of categories involve students in learning and teaching

$\overline{\sum \text { of categories not involve students in learning and teaching }}$

Graphics \& shapes

$\sum$ of categories involve students in learning and teaching

$\overline{\sum \text { of categories not involve students in learning and teaching }}$

Activities

\# of activities the student is required to work on

\# of pages in the textbook

\section{Findings and Discussion}

5.1 Variety of AL Activities Contained in the Natural Science Textbooks for the Intermediate Stage

The types of active learning intellectual, physical, social, in addition to integration activities analyzed activities of the Natural science textbooks series for the intermediate stage.

Table 5. Means and Percentage of active learning activities' types of the Natural Sciences series textbooks of the intermediate stage

\begin{tabular}{llllllllll}
\hline \multirow{2}{*}{$\begin{array}{l}\text { Type of active learning } \\
\text { Activities }\end{array}$} & \multicolumn{1}{l}{ 1st grade } & \multicolumn{3}{l}{ 2nd grade } & \multicolumn{3}{c}{ 3rd grade } \\
\cline { 2 - 11 } & Fre. & $\mu$ & $\%$ & Fre. & $\mu$ & $\%$ & Fre. & $\mu$ & $\%$ \\
\hline Intellectually & 40 & 0.22 & 22 & 29 & 0.18 & 17.9 & 35 & 0.21 & 21.3 \\
Physically & 135 & 0.74 & 74.2 & 130 & 0.80 & 80.2 & 125 & 0.76 & 76.2 \\
Socialy & 7 & 0.03 & 3.8 & 3 & 0.02 & 1.9 & 4 & 0.02 & 2.4 \\
Integration & 27 & 0.15 & 14.8 & 26 & 0.16 & 16 & 24 & 0.15 & 14.6 \\
\hline
\end{tabular}

The Table 5 illustrates that the physical (material) activities are higher than the intellectual and social activities, where the mean of it reached $(0.74,0.80,0.76)$, in the three books respectively. Then the intellectual activities with the mean of $(0.22,0.18,0.21)$ respectively, and the least is the social with very small rate, where its means reached $(0.03,0.02,0.02)$ respectively. Yet, the integration activities with arithmetic means of $(0.15,0.16,0.15)$ in science book, respectively.

This result means that, the activities of the intermediate stage books concentrated on physical activities that require interaction with the material environment and motion while learning to 
do something, and involved the student feebly in the intellectual activities stimulant of critical thinking, analysis and interpretation to build the new knowledge. While abandoned the social activities that concentrate on peers and social work. In addition to poor integration, activities that complement between the main types of activities by rendering the learner involved in intellectual, physical and social activities together at one time, and transfer the student to upper thinking patterns according to Bloom's classification such as analysis, evaluation and innovation.

This finding conform to Fari (2016), Zewdie (2014), and Al-Shahri (2010)). In addition, differ with what (Edwards, 2014) recommended about the need for students to interact with content to achieve intellectual activity among middle school students.

However, this finding refers to that the series of Natural science textbooks for the intermediate stage did not considered the assumptions of cognitive theory for growth. However, books authors had abandoned the features of this age stage and didn't adopt effective teaching methods centered on the student to solve problems and active learning based inquiry in order to employ their potentials for positive learning.

Also, the books had not taken into consideration the balance between types of activities, so books of the intermediate stage exaggerated in bodily activities that formed more than one-third of activities versus great weakness of the intellectual and social activities that represented less than one-third together. The same applies to integration activities, which seemed weak and semi-abandoned in spite of their importance to the intermediate stage.

In addition, this indicates to that the nature of books activities, in general, and- as observed by the researcher- required the leaner to do something, yet dealt with him as a programmable machine implementing a group of ordinal steps to achieve the result predictable. Namely, they concentrated on hands-on without stimulation and minds-on which supposed to associate with doing work, and abandoned the most important constructive assumptions that focus on the role of social bargaining to building knowledge and occurring of learning.

That may be ascribed to the way of selecting educational activities for a lesson, which did not take into account the occurrence of purposeful learning for the lesson objectives, and focused on making the lesson enjoyable only. However, the prevalent belief that active learning occurs through investing teaching strategies by the teacher, and overlooking the role of book in enabling the learner of information detection skills and applying them by themselves.

\subsection{Involvement of Student in AL by the Science Books of Intermediate Stage}

Content analysis of Natural science textbooks series for the intermediate stage was conducted after having determined the analysis units and groups as mentioned before, in addition to, calculation of the number of sentences and drawings, figures and activities, arithmetic means and their percentages. 
Table 6. Means and percentages of the classification of scientific subject matter in series of the natural sciences textbooks of the intermediate stage, graphics, shapes and activities in the light of involvement

\begin{tabular}{|c|c|c|c|c|c|c|c|c|c|c|}
\hline \multirow{2}{*}{$\begin{array}{l}\text { Types of } \\
\text { textbooks } \\
\text { involvement }\end{array}$} & \multirow{2}{*}{ code } & \multicolumn{3}{|c|}{ 1st grade } & \multicolumn{3}{|c|}{ 2nd grade } & \multicolumn{3}{|c|}{ 3rd grade } \\
\hline & & Fre. & $\mu$ & $\%$ & Fre. & $\mu$ & $\%$ & Fre. & $\mu$ & $\%$ \\
\hline \multirow{10}{*}{$\begin{array}{l}\text { Scientific } \\
\text { subject mater }\end{array}$} & $\mathrm{a}$ & 89 & 0.25 & 24.7 & 76 & 0.22 & 22.4 & 65 & 0.24 & 23.5 \\
\hline & $\mathrm{b}$ & 62 & 0.17 & 17.2 & 32 & 0.09 & 9.4 & 34 & 0.12 & 12.3 \\
\hline & $\mathrm{c}$ & 27 & 0.07 & 7.5 & 32 & 0.09 & 9.4 & 22 & 0.08 & 7.9 \\
\hline & $\mathrm{d}$ & 4 & 0.01 & 1.1 & 7 & 0.02 & 2.1 & 6 & 0.02 & 2.2 \\
\hline & $\mathrm{e}$ & 5 & 0.01 & 1.4 & 0 & 0.00 & 0.0 & 0 & 0.00 & 0.0 \\
\hline & $\mathrm{h}$ & 5 & 0.01 & 1.4 & 8 & 0.02 & 2.4 & 6 & 0.02 & 2.2 \\
\hline & $\mathrm{i}$ & 17 & 0.04 & 4.7 & 7 & 0.02 & 2.1 & 7 & 0.02 & 2.5 \\
\hline & $\mathrm{t}$ & 8 & 0.02 & 2.2 & 3 & 0.01 & 0.9 & 2 & 0.01 & 0.7 \\
\hline & $\mathrm{u}$ & 103 & 0.29 & 28.6 & 149 & 0.44 & 43.8 & 113 & 0.41 & 40.8 \\
\hline & $\mathrm{z}$ & 40 & 0.11 & 11.1 & 26 & 0.07 & 7.6 & 22 & 0.07 & 7.9 \\
\hline \multirow{4}{*}{$\begin{array}{l}\text { Graphics, } \\
\text { images, and } \\
\text { shapes }\end{array}$} & $\mathrm{a}$ & 157 & 0.67 & 66.5 & 148 & 0.67 & 66.7 & 168 & 0.70 & 70.0 \\
\hline & $\mathrm{b}$ & 75 & 0.32 & 31.8 & 70 & 0.32 & 31.5 & 66 & 0.28 & 27.5 \\
\hline & $\mathrm{c}$ & 4 & 0.02 & 1.7 & 2 & 0.01 & 0.9 & 4 & 0.02 & 1.7 \\
\hline & $\mathrm{d}$ & 0 & 0.00 & 0.0 & 2 & 0.01 & 0.9 & 2 & 0.01 & 0.8 \\
\hline Activities & - & 182 & 0.47 & 47.4 & 162 & 0.43 & 43.3 & 164 & 0.44 & 43.7 \\
\hline \multicolumn{2}{|c|}{$\#$ of pages in textbook } & \multicolumn{3}{|l|}{384} & \multicolumn{3}{|l|}{374} & \multicolumn{3}{|l|}{375} \\
\hline
\end{tabular}

We notice from the Table 6 that the means, in the sentences that require thinking $(28.6,43.8$, 40.8) are higher than the means of sentences that don't require involving the student in learning and teaching $(24.7,22.4,23.5)$ in the three books respectively. Yet, the mean of drawings, illustrations was higher $(66.5,66.7,70.0)$ in contrast to those which need the use of information or performance of an activity by the student in order to understand $(31.8,31.5$, 27.5). In addition, the involvement coefficient was calculated for each of the following elements: learning scientific material, drawings and figures, and activities using Romey's formula. 
Table 7. Involvement coefficient in the natural sciences series textbook of the intermediate stage in the light of the presentation of scientific subject matter, graphics, shapes and activities

\begin{tabular}{|c|c|c|c|c|}
\hline $\begin{array}{l}\text { Types of } \\
\text { involvement }\end{array}$ & textbooks & $\begin{array}{l}\text { Scientific subject } \\
\text { mater }\end{array}$ & Graphics \& shapes & Activities \\
\hline \multirow{3}{*}{$\begin{array}{l}\text { Involvement } \\
\text { coefficient }\end{array}$} & 1st grade & 0.91 & 0.48 & 0.47 \\
\hline & 2nd grade & 1.29 & 0.47 & 0.43 \\
\hline & 3rd grade & 1.17 & 0.39 & 0.44 \\
\hline
\end{tabular}

Table 7 results show that the value of involvement coefficient, given the presentation of scientific material in the series of Natural science textbooks for the intermediate stage in the three grades, is appropriate and excellent $(0.91,1.29,1.17)$ respectively, where the highest of which was in the second intermediate book. Whereas, the literature indicated that the best and most suitable value of involvement coefficient ranges between (0.4-1.5), and when the value of involvement coefficient exceeds $(0,4)$, the ratio of scientific material, that requires inquiry and research in contrast with the scientific material that doesn't require inquiry, would increase. Results of the study differ with the results of Fari (2016) and Zewdie (2014) that conducted on the same stage books, and the study of Al-Shehri (2010) conducted on the secondary stage books.

This result also, indicates that there is a balance between the sentences that require some thinking with the sentences that don't require the student's engagement. And that the book material gives appropriate amount of active engagement for the student helps him think critically, analyze and practice inquiry in the framework of active learning, and adapt with the scientific material, interact with it in balanced manner, and able to instigate excitement and persistence with the leaner about learning, not taking up the facts and conclusions of authors; which means that science material for the intermediate stage has considered the state standards and could address the leaner, integrate him into its content, and involve him in meaningful learning to the extent that would realize the active learning. This may be due to observance of modern theories in the two fields of learning and education on the part of authors that in line with the directions of the ministry of education in the KSA in the field of curricula development, and consistent with the principles and implications of active learning and constructivist theory.

As demonstrated by the results of Table 7. that the value of involvement coefficient is acceptable, given the graphics and shapes in the series of natural sciences for the intermediate stage in the three grades. Hence, it reached the value of involvement coefficient for the graphics and shapes $(0.48,0.47,0.39)$ respectively; where the value of involvement coefficient for the three books is very close to the acceptable limit of involvement, as indicated by the literature, which is $(0,4)$. Yet, the weakest of all is the science book for the third intermediate grade, so its involvement coefficient tend to be authoritarian. Moreover, this indicates to that the graphics, shapes and pictures provide almost acceptable opportunities to involve the student and motivate him to perform certain activity or use 
additional information, but they provide the greatest number of drawings and illustrations. However, this result conforms to Zewdie (2014) and Al-Shehri (2010). In addition, differs with the study of Fari (2016) which indicated to involvement-elevated level of graphics, shapes and pictures.

The result indicates to that the series of Natural science textbooks for the intermediate stage agree reasonably with the principles and fundamentals of the cognitive theory for growth, which asserts the ability of student, at the intermediate educational stage, to communicate and contact visually and mentally with the scientific material through shapesi, symbols, pictures and graphics. Nevertheless, this is unsatisfactory, where the majority of graphics, shapes and pictures contain illustrations in contrast with those, which involve the learner to perform certain activity, or use information; namely, that they move towards scientific inquiry so slowly not stimulating the learner to effectively think and analyze, and thereby, no suitable educational setting provided for the active learning.

As for the activities, the Table 7 showed that the value of their involvement is acceptable, in the series of Natural science textbooks for the intermediate stage, in the three grades. So, the value of involvement coefficient reached $(0.47,0.43,0.44)$ respectively, where the value of involvement coefficient for the three books are convergent and very close to the involvement limit acceptable as indicated by the literature, which is $(0,4)$. However, this result agrees with the study of Al-Shehri (2010). However, it differs with the study of Fari (2016) which showed a decline in the level of activities contribution coefficient in students' engagement in general science books for the intermediate stage, and the analysis of Zewdie physics books (2014) of the seventh and eighth grades in Ethiopian schools, which elicited that the activities' answers are direct from the books.

This means that books activities are deemed acceptable but unsatisfactory, i.e., they engage the student in practicing processes of thinking and scientific inquiry by a small ratio. This result converge with the involvement result through the presentation of graphics, shapes and pictures; as regards their suitability to the developmental stage of the intermediate stage students, scarcely providing the positive interaction with the scientific content in the book. also means, that all activities of the primary stage science books are a sort of direct activities that present the activities as a cookbook, without engaging the student in the process of thinking and analysis, as they aim to prove the result of experiment announced expressly by the author, without a judgment on the assumptions or even rephrasing them. However, they give little of the student's involvement does not help positively on active learning and scientific inquiry to carry out self-proposed activities.

We deduce from all the above, that the authors of Natural science textbooks series for the intermediate stage, had focused on involving the student in AL through presentation of texts in words more than drawings, pictures and activities, and this may be to their assumption that the age of intermediate stage students requires additional and external support in education by the teacher and parents, and thus, working to provide clear understanding for both parties, upon preparing the lessons before coming to school, in addition to authors' belief of the students inability to implement various scientific activities in the form required. 


\section{Conclusions}

- Authors of natural science textbooks series for the intermediate stage focused on involving the student in AL through the content more than activities, graphics, shapes and pictures.

- Books of science series for the intermediate stage considered the assumptions of cognitive theory for growth, in general, with the learner in the content without the other elements, so they dealt with activities generally with the learner as a programmable machine implements ordinal steps, and overlooked the inquiry-exiting activities, and problem-solving based on AL.

- Imbalance between types of activities, so books exaggerated in bodily activities versus intellectual and social activities, besides to a lower ratio of integration activities, which seemed semi-neglected.

- Books of science for the intermediate stage have neglected the most important constructivist assumptions, which focus on the role of social bargaining to building knowledge and effecting learning.

\section{Recommendations}

- Teachers should take into account the diversity of the forms of student activities in active learning during instruction.

- Consider mental and cognitive level of the learner when planning science curricula, so they, with their elements- content, pictures, drawings, figures and activities- provide an educational environment appropriate for active-learning, provoking thought and analysis, and boost their ability to visual and mental communication with the scientific material to practice scientific inquiry.

- Design, by curricula management and concerned authorities, scientific curricula extend the involvement of students and activate their positive role during the process of learning and teaching, especially in the area of scientific activities, within the standards acceptable, and employ self-detection of information skills during the learning to effect active learning.

- Coordinate between the authorities concerned with composition of books, so that elements of the curriculum-content, activities, drawings, figures and procures- are incorporated together, and be united in their objective of existence together, so they will be connected as we all aspire to in active-learning.

- It's imperative for the authors of science book content, for the intermediate stage, to heed the balance between the types of active learning activities- physical, intellectual and social in addition to concentration on the consolidation activities that integrate between the three types of activities and inquiry activities, from the directed to the open, which would involve the student in a meaningful active-learning. 


\section{Future Research}

- Conduct further evaluative analytical studies for the science books, at different educational stages, given other variables pertaining to active learning. as a study readability of scientific texts of its important role in building effective communication with the book for understanding and self-learning.

- Search how to enhance the teacher's "active learning activities" in the classroom.

\section{References}

Abd-Alsalam, M. (2009). The development of science teaching in the light of modern trends, scientific education: teacher, curriculum, and book invited for review.

Albesher, M., \& Alzahrani, S. (2004). Saudi Arabia's efforts in curriculum development, National Report to the Regional Workshop on Curriculum Development, Muscat, Oman.

Al-Shahri, A. (2010). Evaluation of the content of biology books in the secondary school curriculum. Unpublished Master Thesis, King Saud University, Saudi Arabia.

Bonwell, C., \& Eison, J. (1991). Active Learning: Creating Excitement in the Classroom, Report. Eric Digest

Carr, R., Palmer, S., \& Hagel, P. (2015). Active learning: the importance of developing a comprehensive measure. Active Learning in Higher Education, 16(3), 173-186. https://doi.org/10.1177/1469787415589529

Chan, Y., Sidhu, G., \& Lee, L. (2014). Active Learning in Higher Education: A Case Study, Conference Paper. Taylor's $7^{\text {th }}$ Teaching and Learning Conference 2014 Proceedings, 519-526.

Edwards, S. (2015). Active learning in the middle grades classroom: Overcoming the barriers to implementation. Middle Grades Research Journal, 10(1).

Edwards, S. (2014). Getting them to talk: A guide to leading discussions in middle grades classrooms. Westerville, $\mathrm{OH}$ : Association for Middle Level Education.

Edwards, S., Kemp, A., \& Page, C. (2014). The middle school philosophy: Do we practice what we preach or do we preach something different? Current Issues in Middle Level Education, 19(1), 13-19.

Fagehe, Y. (2009). Where are we from? Programs and projects of reforming global of Science education. Knowledge magazine, 169.

Fari, A. N. (2016). The extent of the general science books' contribution in the engagement of basic level students in learning from the point of view of teachers in Jenin governorate. An-Najah National University, Nablus, Palestine.

Handelsman, J., Miller, S., \& Pfund, C. (2007). Scientific teaching. New York: W.H. Freeman.

Harrison, A. j. \& Sipay, E. R. (1990). How to increase reading ability (9th ed.) Longman.

Khataibeh, A. (2008). Science Education for All. Amman. Dar Al-maserah.

Ministry of Education (MOE). (2006). Project of developing mathematics and natural sciences curricula in Saudi Arabia. Secretariat of the project of developing mathematics and 
natural sciences curricula, printing presses

National Commission on Excellence in Education (1983). A Nation at Risk: An Imperative for Educational Reform. A Report to the Nation and the Secretary of Education United States Department of Education. Retrieved from_http://www.ed.gov/pubs/NatAtRisk/risk.html

National Middle School Association (NMSA). (2010). This we believe: Keys to educating young adolescents. Westerville, $\mathrm{OH}$ : Author.

Nesin, G. (2012). Active Learning. This we believe in action: Implementing successful middle level schools (pp. 17-27). Westerville, OH: Association for Middle Level Education.

Shannon, J., \& Mayes M. (2011). The Risk of Active Learning in the Classroom: Negative Synergy and its implications for Learning. International Journal of Business and Social Science, 2(14).

Zaytoon, A. (2010). Contemporary International Trends in Science Curricula and their Teaching Methods, Dar- Ashorauq publishers, Amman

Zewdie, Z. M. (2014). Analysis of Grades 7 and 8 Physics Textbooks: A Quantitative Approach. American Journal of Educational Research, 2(1), 44-49. https://doi.org/10.12691/education-2-1-8

\section{Copyright Disclaimer}

Copyright reserved by the authors.

This article is an open-access article distributed under the terms and conditions of the Creative Commons Attribution license (http://creativecommons.org/licenses/by/3.0/). 